\title{
Early discharge after atrial fibrillation ablation
}

\author{
Alta temprana tras la ablación de fibrilación auricular \\ Carlos Escobar-Cervantes, Sergio Castrejón, Andreu Porta, Óscar Salvador, José A. Cabrera, and \\ José L. Merino* \\ Hospital Universitario Quirón Ruber Juan Bravo, Madrid, Spain
}

Atrial fibrillation (AF) ablation has been shown to generally be an effective procedure with low risk of complications ${ }^{1}$. However, maintaining the patient hospitalized at least $24 \mathrm{~h}$ after the procedure is common practice, to early detect possible complications. Consequently, mean lengths of stay up to 4 days after this procedure have been reported, without this practice apparently improving patient evolution ${ }^{2}$. Given the increasing number of $\mathrm{AF}$ ablation procedures ${ }^{1}$, excessive costs of prolonged stay, as well as the care demand pressure that exists at our setting, it is important to know if early hospital discharge $(<24 \mathrm{~h})$ of these patients is possible after AF ablation.

The purpose of this study was to assess the safety of early hospital discharge $(<24 \mathrm{~h})$ after AF ablation. To this end, all consecutively included patients were analyzed in an AF ablation program at a hospital center. All patients granted written informed consent before executing the intervention. Patient enrollment was carried out between May 2013 and May 2018, at a hospital with an intermediate volume of annual procedures. In all patients, the ablation procedure was practiced through three to four vascular accesses using the right femoral vein and without stopping anticoagulant medication, if they were taking it previously (Vitamin $\mathrm{K}$ antagonists or direct oral anticoagulants). At the beginning of the procedure, a $100 \mathrm{U} / \mathrm{kg}$ bolus of heparin was administered, followed by infusion. Activated coagulation time was not monitored during the procedure and no intracardiac ultrasound was used except in one patient undergoing AF cryoablation and in another with multielectrode circular catheter; in the rest of the patients, ablation was carried out by circumferential isolation of the four pulmonary veins with point-to-point application of radiofrequency and $30-40 \mathrm{~W}$ and $45^{\circ} \mathrm{C}$ parameters. At the end of the procedure, the vascular introducer sheaths were removed without systematically using protamine for coagulation reversal. Hospital discharge was scheduled $<24 \mathrm{~h}$ after admission by nursing staff without prior medical visit unless incidents occurred. All patients received hospital discharge under anticoagulation treatment.

One hundred and three patients were included (mean age, $60.8 \pm 9.9$ years, with $80.6 \%$ of males). Paroxysmal $\mathrm{AF}$ was identified in $71.8 \%$ and the rest had persistent AF. In all patients, isolating all pulmonary veins was possible. Mean time of the procedure was $168.3 \pm 43.1 \mathrm{~min}$. There were no acute complications, with the exception of a cardiac tamponade resolved by pericardiocentesis, which prolonged hospital stay to $36 \mathrm{~h}$. Using protamine was necessary only in this patient $(100 \mathrm{mg})$ as well as in other five individuals for local hemostasis $(25 \mathrm{mg}$ in

\section{Correspondence:}

*José L. Merino

Hospital Universitario Quirón Ruber Juan Bravo

Juan Bravo, 49

Date of reception: 10-02-2019

Date of acceptance: 17-04-2019

E-mail: jlmerino@arritmias.net

DOI: 10.24875/ACME.M20000073
Available online: 13-09-2019

Arch Cardiol Mex (Eng). 2019;89(4):374-375

www.archivoscardiologia.com 2604-7063/@ 2019 Instituto Nacional de Cardiología Ignacio Chávez. Published by Permanyer. This is an open access article under the CC BY-NC-ND license (http://creativecommons.org/licenses/by-nc-nd/4.0/). 
1 and $50 \mathrm{mg}$ in 4). After examination of the vascular puncture site by nursing staff, $102(99.0 \%)$ patients were discharged in $<18 \mathrm{~h}$ after the start of the procedure (mean hospital length of stay, $15.3 \pm 1.3 \mathrm{~h}$ ). A transthoracic echocardiogram was performed in 12 patients before hospital discharge (11 scheduled and one for chest discomfort) without significant alterations being identified. Echocardiogram was performed, particularly in fragile individuals, to ensure that there were no complications. It was not systematically carried out. During follow-up, there was only one complication (1.0\%), an arterial pseudoaneurysm on day 3 after discharge, which required surgical repair.

International scientific societies current recommendations do not tell when should hospital discharge after AF ablation be indicated ${ }^{1}$. In addition, currently available information is quite scarce, limited to a few publications $^{3-5}$. In a recent publication on patients undergoing cryoablation for AF in a London center, with a rate of total complications of $5-6 \%$, only $1.4 \%$ of patients were not discharged within the first $24 \mathrm{~h}$ after the procedure ${ }^{3}$. The difference in the number of complications with the authors' study may be due, among other reasons, to the different techniques used (radiofrequency in this case versus cryoablation, with a higher risk of phrenic nerve injury). In a recent communication of a scientific congress, which included 124 patients from one center in California, mean hospital length of stay was $17.5 \mathrm{~h}^{4}$. In another scientific communication in a congress of a hospital in Vancouver, AF ablation early discharge was accompanied by higher patient satisfaction in comparison with longer stays, as long as patients had enough information about the procedure, on possible complications and on what to do in case of the occurrence of any complications ${ }^{5}$. In Spain, there are no published data on the effect of early discharge on safety and risk for complications in patients undergoing AF ablation. This series indicates that, in Spain, hospital discharge within the first $24 \mathrm{~h}$, and even within the first $18 \mathrm{~h}$ after the procedure, is safe and feasible, with similar results to those recently described in other countries.

\section{Conclusion}

Early hospital discharge in $<24 \mathrm{~h}$ after AF ablation is feasible and apparently safe, which might have important implications in health organization and on the costs related to the procedure.

\section{Funding}

This work has not received any funding.

\section{Conflicts of interest}

The authors have no conflicts of interest with regard to this publication.

\section{Ethical disclosures}

Protection of people and animals. The authors declare that the procedures that were followed complied with the ethical standards of the responsible human experimentation committee and were in accordance with the World Medical Association and the Declaration of Helsinki.

Confidentiality of data. The authors declare that they have followed the protocols of their work center on the publication of patient data.

Right to privacy and informed consent. The authors declare that no patient data appear in this article.

\section{References}

1. Calkins H, Hindricks G, Cappato R. 2017HRS/EHRA/ECAS/APHRS/SOLAECE expert consensus statement on catheter and surgical ablation of atrial fibrillation: executive summary. Europace. 2018;20:157-208.

2. Opolski G, Januszkiewicz $\measuredangle$, Szczerba E. Readmissions and repeat procedures after catheter ablation for atrial fibrillation. Cardiol J. 2015;22:630-636.

3. Opel A, Mansell J, Butler A. Comparison of high throughputday case atrial fibrillation ablation service in a local hospitalwith standard regional tertiary cardiac centre care. Europace. $2018 \mathrm{Jul} 30$. [Epub ahead of print].

4. Nitzany E, Liem LB, Chen S, Kaiser DW, Merriott S. Same day discharge in atrial fibrillation ablation procedure- a single center experience. ACC Quality Summit NCDR 2018 Annual Conference, March 2018.

5. Forman J, Gwozd T, Deyell M. Improving patients' experience of sameday discharge after atrial fibrillation ablation. Can J Cardiol. 2018;34 (Suppl 1):S210-211.N029. 